\title{
The generation and use of bird population indicators in Europe
}

\author{
RICHARD D. GREGORY, PETR VOŘIŠEK, DAVID G. NOBLE, ARCO VAN \\ STRIEN, ALENA KLVAŇOVÁ, MARK EATON, ADRIAAN W. GMELIG \\ MEYLING, ANDREW JOYS, RUUD P.B. FOPPEN and IAN J. BURFIELD
}

\section{Summary}

Global and regional targets to reduce the rate of biodiversity loss bring with them the need to measure the state of nature and how it is changing. A number of different biodiversity indicators have been developed in response and here we consider bird population indicators in Europe. Birds are often used as surrogates for other elements of biodiversity because they are so well known and well studied, and not for their unique intrinsic value as environmental indicators. Yet, in certain situations and at particular scales, trends in bird populations correlate with those of other taxa making them a valuable biodiversity indicator with appropriate caveats. In this paper, we look at two case studies, in the UK and Europe as a whole, where headline bird indicators, that is, summary statistics based on bird population trends, have been developed and used to inform and assist policy makers. Wild bird indicators have been adopted by many European countries and by the European Union as indicators of biodiversity and of sustainable development. In the discussion, we review the strengths and weaknesses of using bird populations in this way, and look forward to how this work might be developed and expanded.

\section{Introduction}

There is growing recognition across the globe that the inexorable decline in the state of nature may have profound consequences for the lives of people and their economies through the loss of the natural resources and the ecological services they provide (Carpenter et al. 2006: http:// www.millenniumassessment.org/en/index.aspx). There is an equally compelling call for biodiversity to be conserved for its intrinsic and irreplaceable value to mankind. In recognition of this threat, European Union member states agreed in 2001 an ambitious target to halt biodiversity loss by 2010, an aim that was later confirmed at a pan-European level through the Kyiv Resolution on Biodiversity. At a global scale, in 2002 at the COP6 of the UN Convention on Biological Diversity (CBD), and the Johannesburg World Summit on Sustainable Development, world leaders agreed to achieve by 2010 a significant reduction of the current rate of biodiversity loss at the global, regional and national level as a contribution to poverty alleviation and to the benefit of all life on Earth. The framework provided by the target has been influential in guiding and streamlining the policy response across the globe. This process relies on headline CBD 'indicators' i.e. summary statistics to report on progress towards meeting the target and hence to further inform the response (http://www.cbd.int/2010-target/default.shtl).

The meaning of an indicator is as a surrogate for a parameter that is too ephemeral or too difficult technically, practically or too expensive, to measure directly (Landres et al. 1988, Hilty and Merenlender 2000, Lindenmayer et al. 2000, Gregory et al. 2005). Good examples are lichens indicating air quality (McClenahen et al. 2007), plant species indicating soil moisture or soil fertility, or bird of prey populations reflecting pesticide contamination (Furness and 
Greenwood 1993). Such indicators are often used in research and wildlife management as diagnostic tools to gain specific knowledge about the environment. Currently, however, the terms indicator, indicator species, signal species, bio-indicator or bio-monitor, can have different meanings and functions, which can be confused (Caro and O'Doherty 1998, Hilty and Merenlender 2000, Landres et al. 1988, Lindenmayer et al. 2000, Gregory et al. 2005, 2007). Headline biodiversity indicators are a unique type of indicator that we believe deserve special attention. The purpose of a headline indicator is to provide simple immediate information to policy-makers, decision-makers and the general public - in this instance about progress towards meeting targets for halting biodiversity loss. Contrary to indicators used in adaptive wildlife management that measure specific elements and dimensions of biodiversity, the headline indicators are meant to tell the 'general story' rather than to provide detailed information. For indicators to be effective, they need to meet a range of sometimes competing practical and scientific criteria (Bibby 1999, Balmford et al. 2005, Gregory et al. 2005). This is especially important for headline indicators because communication is central to their value in telling us about the 'big picture'. Headline indicators are not a substitute for the detailed knowledge needed to assess the causes of change in individual species, or ecosystems, and then to formulate strategies in response (Bibby 1999). We view reporting on progress towards such biodiversity targets using indicators as a vital part of an effective monitoring programme, although this function was overlooked in a recent critical review of monitoring (Nichols and Williams 2006).

\section{Case study 1: Bird population indicators in the UK}

\section{Development and data sources}

The idea of developing a wildlife indicator came from an expert group set up by what is now the Department of Environment, Food and Rural Affairs (Defra) to review suitable indicators to underpin the 1999 UK Sustainable Development Strategy (Gregory et al. 2004). This group identified a number of wildlife indicators reflecting traditional conservation issues, such as the number and condition of special sites, the number and status of priority species and habitats, the proportion of species that are threatened, and so forth. What was recognised as a key gap, however, was the lack of broader indicators reflecting the general health of common and widespread wildlife in the countryside. This is where the notion of developing a wild bird indicator came from. Although initial discussions focussed on target-based indicators (Bibby 1999), the Royal Society for the Protection of Birds (RSPB), the British Trust for Ornithology (BTO) and Defra developed the idea to create a state indicator: one that reflected the broad state of nature without requiring targets for individual species. Birds were chosen because they are regarded as good general indicators of the state of wildlife; they are wide-ranging in habitat use and tend to be at, or near, the top of the food chain; there is good trend information available from the early 1960s; and they have great public resonance, and hence were judged to be an excellent way to raise awareness of biodiversity issues.

A whole range of data sources are available on bird trends in the UK and the indicators that were developed attempted to make maximum use of what was available (Gregory et al. 1999, 2003). At present, the main data sources are annual surveys such as the BTO's Common Birds Census (CBC), the BTO/JNCC/RSPB Breeding Bird Survey (BBS), the BTO/WWT/RSPB/JNCC Wetland Bird Survey, the BTO Waterway Birds Survey, the JNCC Seabird Monitoring Programme and a small number of special surveys. For each species, we used the best dataset available considering representativeness, the time period covered by the survey and its periodicity.

\section{Aims of the indicator}

The UK wild bird indicator was designed to be a state indicator comprising common native species, with each species weighted equally. It is a composite indicator integrating the balance of 
population trends of a basket of species and is potentially sensitive to a number of different drivers and pressures in the environment (ones we perceive now and potential unforeseen emerging issues). Its purpose was to act as a barometer of environmental change and as a surrogate of changes in wildlife more broadly.

\section{Indicator methods}

Methods are described in Gregory et al. (1999, 2003) and here we provide a brief summary. Data for constituent species are analysed, usually in a General Linear Modelling framework, to provide annual parameter estimates of abundance. Where necessary, values for missing years are estimated by interpolation and values for years outside the period covered by the survey are estimated by extrapolation, using pre-defined rules to maintain sufficient robustness. The annual indices for each species are then standardised to a common start year, and the annual indicator values are determined from the geometric mean of the constituent species values. Geometric means are used as the indices to present proportional change so that an index change from 100 to 200 (a doubling) is equivalent, but opposite, to an index change from 100 to 50 (a halving).

\section{Species and habitat selection}

Originally, the indicator focussed on two key groups, farmland and woodland birds, as they and their habitats are found across most of the UK countryside. It was based on common native bird species (i.e. those having more than 500 breeding pairs in the UK around 1990). Species were classified to habitat using Gibbons et al. (1993), who assigned species to habitats according to where they predominately breed and forage. Once allocated to a habitat, the trend for a species is generated using all available data, which in many cases will include those collected in other habitats - for example, trends for many woodland species will be based partly on data collected in farmland. This treatment is driven by the data because the CBC, which began in the 196os, comprised survey plots defined as either farmland, woodland or special habitats.

More recently, and with the advent of the BBS covering a stratified sample of habitats from 1994, genuine habitat-specific indicators have been developed for birds of water and wetland (in England), towns and gardens (England), uplands (Scotland) and seabirds (England, Scotland, UK), as measures of changes in biodiversity in these species groups. By habitat-specific, we mean building indices based on species' trends taken from specific habitats only (Newson et al. 2004). For the sake of consistency, and because the trends were so similar, the original farmland and woodland bird indicators have remained unchanged (Newson et al. 2004). The indicator work has demonstrated gaps in monitoring of key habitats, such as uplands, as well as the need to develop objective methods for determining representative species for each habitat. The town and garden indicator employed this kind of approach as many generalist species widespread across a number of habitats use urban areas, but few can be defined as specialists (i.e. only five are so defined by Gibbons et al. 1993). Therefore, the occurrence of species within urban transect-sections of the BBS was used to determine species inclusion, and only data from these transect sections was used in the generation of trends used to calculate the indicator.

The seabird indicator (now included in the main headline indicator) is based upon the monitoring of numbers at breeding colonies, but as long-lived seabirds may not show the population-level impact of reduced breeding success for some years, a complementary indicator based on annual productivity has also been developed. This makes use of good information on year-to-year changes in productivity, hence illustrating the worrying run of breeding failures at some sites in recent years. Finally, a suite of wintering waterbird indicators, reporting on the UK's internationally important populations of wintering waterfowl and waders, are produced using data collected annually through the Wetland Bird Survey and WWT Goose Counts. 
Arguably, one of the weaknesses of such indicator sets in terms of biodiversity as a whole is that the rare and scarce species are underrepresented. This comes about because general bird surveys tend to focus on the commoner species by default - one requires more intensive survey methods and a specific sampling framework to census rare species. In this way, the wild bird indicator misses an important component of biodiversity and this emphasises the need for complementary measures that focus on rare species (van Strien 1999, Butchart et al. 2004, 2007). The population trends of rare birds, however, were excluded deliberately from the UK indicator because they are mostly the focus of dedicated conservation actions, are concentrated at a relatively small number of sites, and for this reason not particularly representative of the wider countryside (Gregory et al. 2003). In fact, a rare bird indicator developed by Gregory et al. (2003) showed populations to have more than doubled in the UK in the last 30 years, reflecting considerable investment of time and money in proactive and largely successful conservation initiatives. It would therefore be quite misleading to assume that the population trends of rare birds were representative of the countryside in general, at least in this case.

\section{Developing country/regional versions}

Devolution in UK, regionalisation of decision making in England, and commitments to local and regional Biodiversity Action Plans, have led to the development of bird indicators at sub-national scales too. The index procedures used are identical to those above and a suite of useful countrylevel indicators has now been produced for the England and Scotland Biodiversity Strategies, and in Wales. However, lack of sufficient data at these smaller scales often constrains the number of species that can be reliably included in the indicators, and may bias species selection towards those that are faring well, influencing the overall indicators and limiting their value. We have worked on ways to improve the information and indicators at smaller scales, but scarcity of count data in some areas is hard to overcome.

\section{Trends of common and widespread birds in the UK}

The UK and England wild bird indicators (Figure 1a,b) show marked declines in farmland birds and shallower but significant declines in woodland birds over the past four decades. A large body of research shows that the main driver of farmland bird declines, along with the parallel declines of other animals and plants in the UK, has been increased agricultural intensification (e.g. Aebischer et al. 2000, Vickery et al. 2004), although factors such as climate change, predators and changes in other habitats also influence the trends of some species. In contrast, the seabird indicator has increased markedly since the 1970s, largely because of increases in the availability of fishing discards and breeding expansion in a group of opportunistic species. The seabird trend has faltered in the past decade as recent wide scale breeding failures start to have an impact on breeding populations.

Focussing on the indicators that underpin the England Biodiversity Strategy, we can see that specialist birds of both farmland and woodland have declined disproportionately compared with generalists in the same habitat (Figure $2 \mathrm{a}, \mathrm{b}$ ). Most breeding birds associated with wet habitats are increasing, but among this group, there are significant declines in species of wet meadows and of fast-flowing upland streams and rivers. In contrast, birds of towns and gardens show evidence of increase, reflecting increasing reliance on urban and suburban habitats by a group of widespread, mainly generalist species.

Regional BBS-based indicators, covering a much shorter period due to a reliance on these data, show contrasting fortunes in different areas, with populations of farmland and woodland birds faring better in the north than in the south. This probably reflects the continuing pressures on already scarce woodland and highly intensive farmland in many areas of southern Britain (Figure 3 ).

It is relevant at this point to reflect on the question of the degree to which bird trends can tell us about the trends in other elements of biodiversity, and perhaps surprisingly, this is a 
(a)

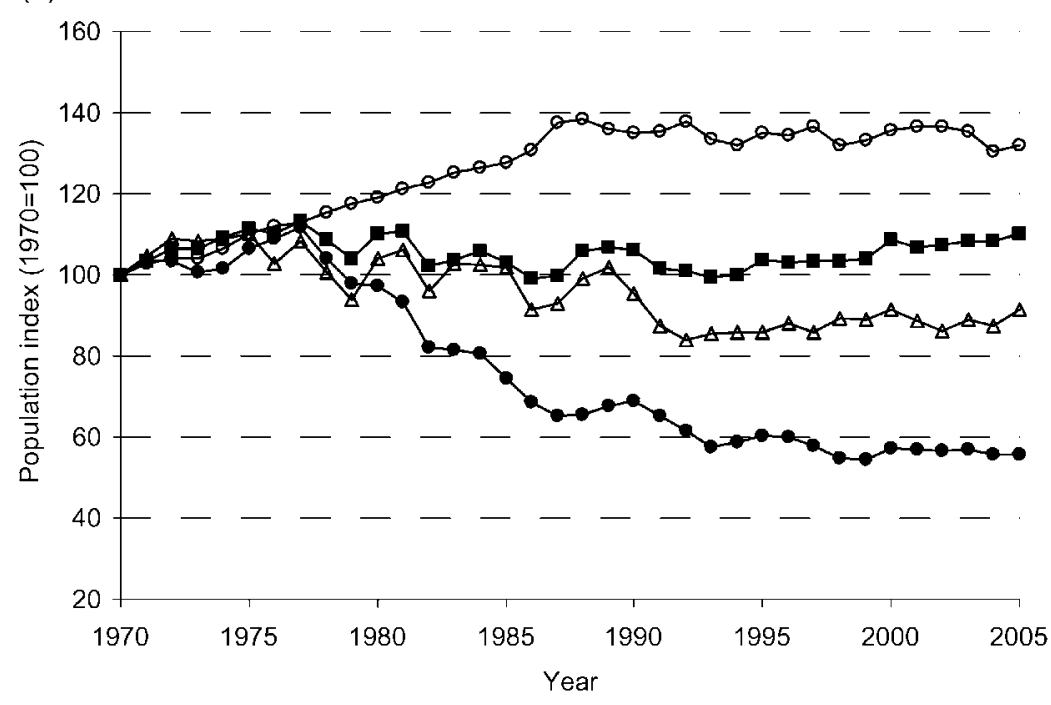

(b)

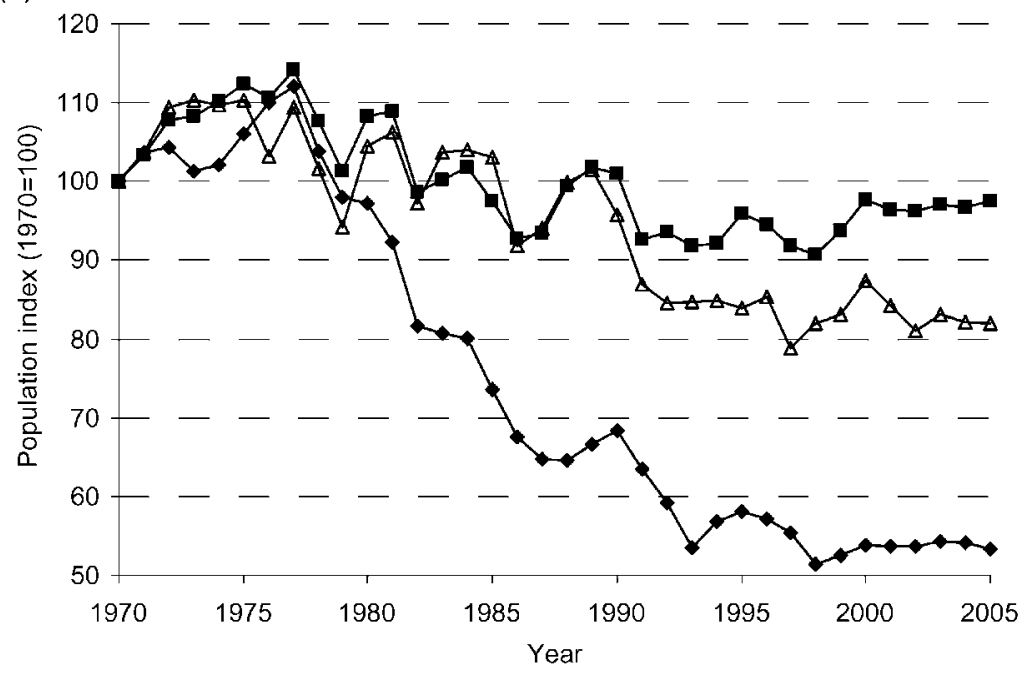

Figure 1 . Wild bird indicators in the UK. (a) The UK wild bird indicator showing trends in widespread and common seabirds $(n=20$, open circles, $+30 \%)$, woodland birds $(n=33$, open triangles, $-9 \%)$, farmland birds $(n=19$, filled circles, $-44 \%)$, and all common species $(n=$ 113 , filled squares, $+10 \%$ ). (b) The England wild bird indicator showing trends in woodland birds ( $n=33$, open triangles, $-18 \%)$, farmland birds $(n=19$, filled diamonds, $-47 \%)$, and all common species $(n=96$, filled squares, $-2 \%) . n=$ number of species included in each multispecies indicator. Change figures are percentage changes in the indices from 1970 to 2005.

somewhat neglected area of research. Gregory et al. (2005) summarised the evidence linking farmland bird trends with those of other taxa and showed considerable concordance, whereas for forest birds the linkages are much less clear and more research is required (Gregory et al. 2007). 
R. D. Gregory et al.

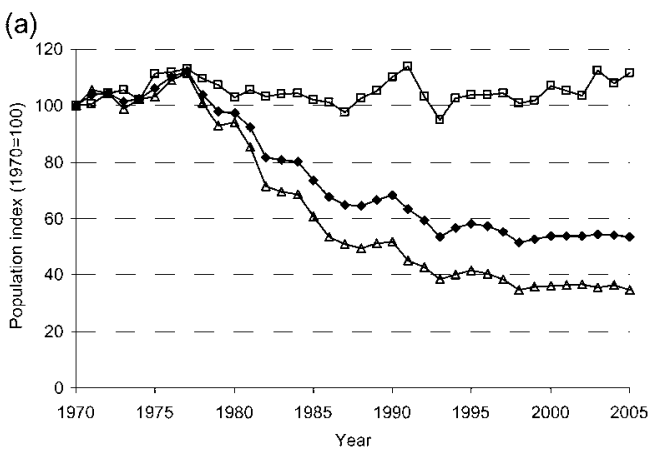

(b)

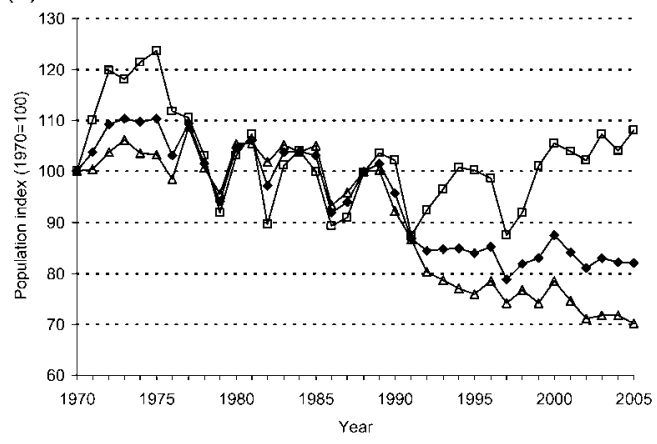

(c)

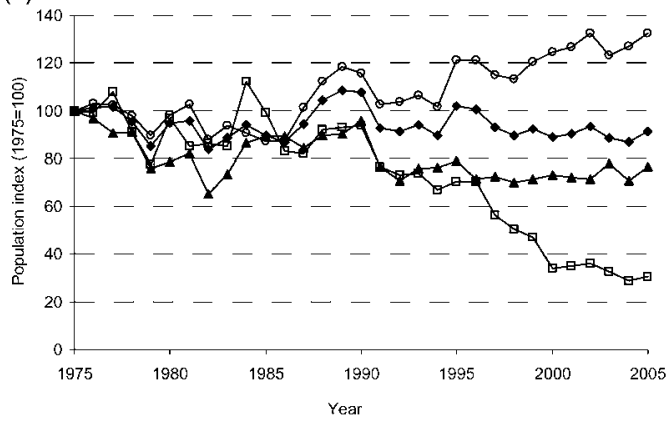

(d)

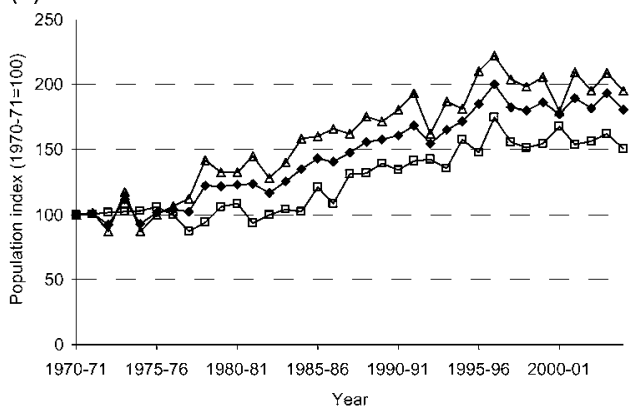




\section{Turning science into policy}

The wild bird indicators described above are produced annually by a group of government and non-government organisations. The most recent update and details can be found on http:// www.defra.gov.uk/environment/statistics/wildlife/ $\mathrm{kf} / \mathrm{wdkfo}$. htm alongside other indicators of sustainable development on a diverse array of topics including priority species and habitats, public attitudes, protected area networks, waste and recycling and water quality. The methodological development of the wild bird indicators in the UK has provided impetus for complementary indicators of biodiversity based on data for taxa such as butterflies and bats. The UK headline wild bird indicator (covering farmland birds, woodland birds and seabirds) was selected as one of 20 high-level UK sustainable development Framework Indicators, which are designed to monitor the priority areas for action identified by the strategy (http:// www.sustainable-development.gov.uk/progress/national/framework.htm). This has resulted in a high profile for the bird indicators, equivalent to that of other Framework Indicators that are more familiar to the public, such as employment, poverty, education and life expectancy.

Wild bird population indicators based solely on English data, with a breakdown for farmland, woodland, water and wetland, towns and gardens, coasts and seas, are also used for measuring progress of the England Biodiversity Strategy (http://www.defra.gov.uk/wildlife-countryside/ biodiversity/biostrat/indicators/index.htm ). Similar country-based initiatives are underway in Scotland (http://www.scotland.gov.uk/Publications/2004/06/19410/37926) and in Wales.

The UK Government's response to the plight of farmland birds came in the form of a Public Service Agreement with a public pledge to "care for our living heritage and preserve natural diversity by reversing the long-term decline in the number of farmland birds by 2020 , as measured annually against the underlying trends". With this came a detailed delivery plan that identified targets, the time scale, and actions necessary to meet this aim. The target would be judged met when the long-term trend is significantly positive, as measured by a statistically smoothed version of the English farmland bird indicator (Figure 4: Gregory et al. 2004). Although the target could in theory be achieved by an increase in the generalist species alone, while specialists still declined, the Government's aim was to bring each species into a stable or increasing position and then to safeguard and sustain that achievement into the future.

The policy response was a new agri-environment scheme, called the Environmental Stewardship Scheme, which was introduced in 2005. An entry-level option was open to all farmers and rewarded them financially for delivering wildlife habitats, and for soil and water management. The aim was for $70-90 \%$ of farmers to take it up. On top of this was a higher-level option that rewarded farmers financially for delivering more advanced management prescriptions designed to bring significant environmental benefits. The uptake aim was $10 \%$. The options included hedgerow management, grass field margins, growing wild bird cover crops, retaining stubble, summer fallow and under-sown crops, introducing conservation headlands and open skylark patches in crops, and so on. One of the key elements in the response was that the government agencies and NGOs worked hand in hand to develop prescriptions that were both practically and economically viable and efficient, but delivered the maximum benefit for wildlife.

Figure 2. Wild bird indicators in the England Biodiversity Strategy. (a) Farmland birds, all species ( $n=19$, filled diamonds, $-47 \%)$, generalists $(n=7$, open squares, $+11 \%)$, and specialists ( $n=12$, open triangles, $-66 \%)$. (b) Woodland birds, all species $(n=33$, filled diamonds, $-18 \%)$, generalists $(n=12$, open squares, $+8 \%)$, and specialists $(n=21$, open triangles, $-30 \%)$. (c) Breeding birds of water and wetlands, all species $(n=21$, filled diamonds, $-9 \%)$, fast $(n=3$, filled triangles, $-23 \%)$, slow/still waters $(n=14$, open circles, $+32 \%)$, and wet meadows $(n=4$, open squares, $-69 \%)$. (d) Wintering waterbirds, all species $(n=35$, filled diamonds, $+81 \%)$, waders $(n=12$, open squares, $+51 \%)$, and wildfowl and allies $(n=19$, open triangles, $+95 \%$ ). $n=$ number of species included in each multi-species indicator. Change figures are percentage changes in the indices from 1970 to 2005. 

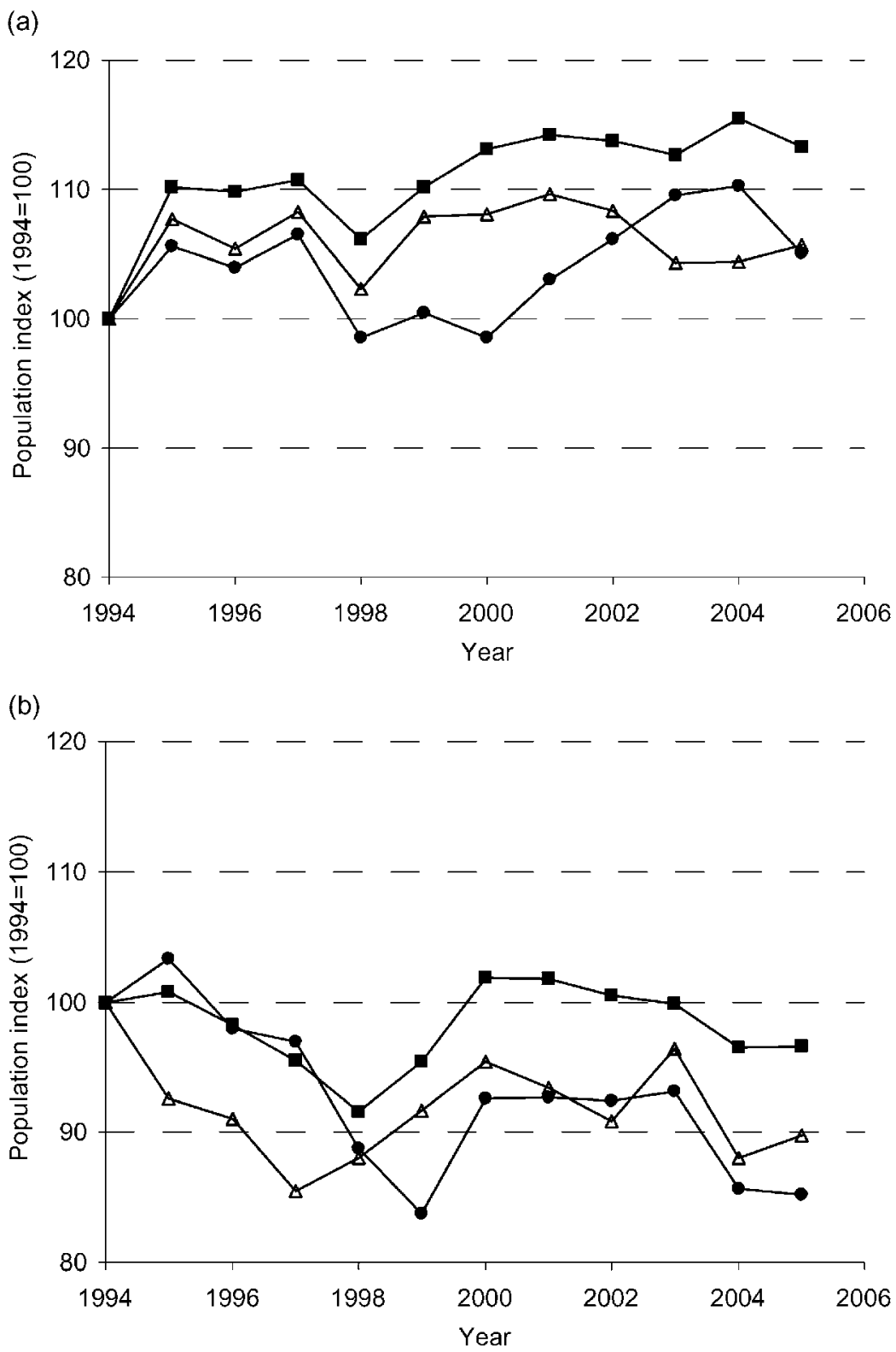

Figure 3. Wild bird indicator for English government regions: (a) north-east England, woodland birds ( $n=31$, open triangles, $+5 \%$ ), farmland birds ( $n=18$, filled circles, $+6 \%$ ), and all common species $(n=87$, squares, $+13 \%)$ and (b) south-east England, woodland birds $(n=28$, open triangles, $-10 \%)$, farmland birds $(n=19$, filled circles, $-15 \%)$, and all common species $(n=$ 79 , squares, $-3 \%)$. $n=$ number of species included in each multi-species indicator. Change figures are percentage changes in the indices from 1994 to 2005. 


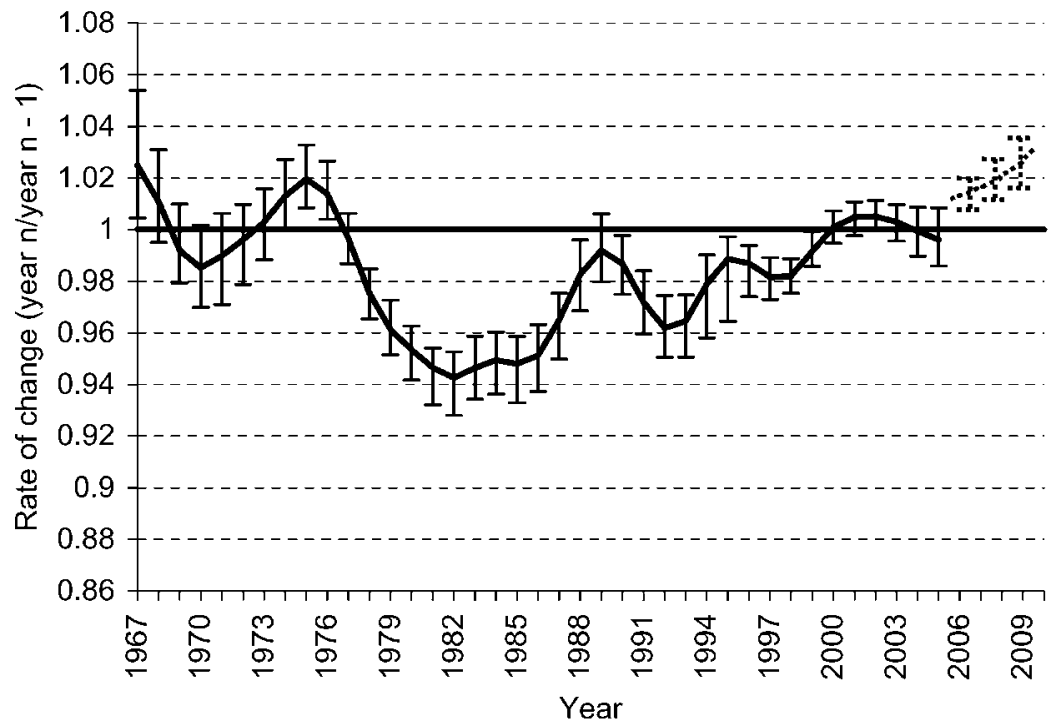

Figure 4. How the UK farmland bird target is measured. Here a statistically smoothed version of the farmland bird index for England is presented as a proportion of the previous year's index with bootstrapped $95 \%$ confidence limits on the proportional change. Values above one indicate that the index has increased on the previous year, those below one show it has declined between years. There is no statistically significant change when the confidence limits overlap one. The government's target, illustrated on the right of the figure, is for farmland birds to be increasing in a statistically significant fashion.

Three years on, the entry-level option has proved popular with over half of farmers subscribing to the scheme and continued uptake is expected. Uptake of the higher-level option however has been very poor to date. Analyses are underway to compare patterns of uptake of different options and assess the need for changes to the scoring system or additional options. Importantly, changes in populations of farmland birds, particularly those species in the Farmland Bird Index, during the early years of the scheme will be used to measure its success, and to inform any changes to its implementation.

The woodland bird indicator has been adopted by the UK government's Forestry Commission as an indicator of sustainable forestry along with a target to reverse the long-term decline in the number of woodland birds in England by 2020.

The wild bird indicators we describe are increasingly being used to inform debate on the state of birds and hence biodiversity at national and sub-national levels. Indices are being developed for different bird groups and habitats covering both breeding and wintering populations, and in some cases, trends in productivity are being used alongside population trends. In the future, indicators may be used to describe other demographic changes and demographic, distribution and population data may be increasingly used to create indicators of the impacts of climatic change.

\section{Case study 2: Bird population indicators in Europe}

\section{Development and data sources}

Ambitions to bring together bird population monitoring of various kinds in Europe go back many years. The advantages of pooling and comparing data are obvious from both scientific and 
conservation policy perspectives. These ambitions have been given sharper focus and prominence in recent years because of the adoption of biodiversity targets by World and European leaders. BirdLife International has published two comprehensive reviews of populations and trends of all European birds (Tucker and Heath 1994; BirdLife International 2004), and the first attempts to compile and assimilate European trend data for land birds go back to Hustings (1988, 1992). Arguments for establishing pan-European monitoring for breeding birds have been led by the European Bird Census Council and BirdLife, involving three international workshops, and considerable consultation and discussion (Gibbons 1998, 2000; Gregory and Vořišek 2003). From the outset, the work was strongly influenced by the experiences in developing workable indicators in UK and by parallel work in The Netherlands. Developing such an initiative at a European scale raised many new issues and challenges. Having considered a number of different options, the favoured one was 1 ) building a pan-European scheme for common breeding birds by combining data from the pre-existing national count schemes, 2) encouraging and initiating new schemes in those countries with the capacity to do so, and 3) building similar capacity and establishing a sample of survey plots in the remaining countries. Progress under the banner of the 'Pan-European Common Bird Monitoring Scheme' (PECBMS) has been considerable (Gregory et al. 2005, 2007, see: http://www.ebcc.info/pecbm.html). The real catalyst for progress was the establishment of the PECBMS and the appointment of a full time project co-ordinator in 2002, funded by the RSPB.

A recent review of large-scale common bird monitoring schemes in Europe found information on 52 count schemes in 35 countries (http://www.ebcc.info/pecbm.html). When compared with the last review of its kind (Vořišek and Marchant 2003), the new findings showed that the number of count schemes for common birds was increasing while at the same time the standards of survey design and analysis were improving - all very encouraging signs of growth and development in this area of biodiversity monitoring, which can claim to be amongst the most advanced elements of environmental recording in Europe. In the latest set of wild bird indicators presented here, information derived from annually operated national breeding bird surveys spanning different periods came from 20 European countries (see below). In the next few years, we anticipate several more countries being able to contribute data in this way.

\section{Aims of the indicator}

As with the UK wild bird indicator, the European wild bird indicator was designed to be a state indicator comprising common native species, with each species weighted equally. It is a composite indicator integrating the balance of population trends of a basket of species and it is potentially sensitive to a number of different drivers and pressures in the environment (ones we perceive now and potentially unforeseen emerging issues). The overall purpose was for this indicator to act as a barometer of environmental change in Europe and as a surrogate of changes in nature.

\section{Indicator methods}

Methods were trialled in van Strien et al. (2001), and implemented by Gregory et al. (2005, 2007). Here we give a brief summary of the methods. Bird trend information was collated by the PECBMS. The software package TRIM (Pannekoek and van Strien 2001), which allows for missing counts in the time series and yields unbiased yearly indices and standard errors using Poisson regression, was used to calculate national species' indices. Next, TRIM was used to combine the national species indices into supranational indices for species, weighted by estimates of national population sizes. Weighting accounts for the fact that different countries hold different sizes of each species' European population. National trends were combined in a hierarchical fashion so that missing values were estimated from similar neighbouring countries. 
Supranational indices for species were then combined on a geometric scale to create multi-species indicators (Gregory et al. 2005, 2007).

\section{Species and habitat selection}

It was our intention for these indicators to tell us something about how the environment might be changing at a broad scale, so we have focussed on the predominant landscapes of Europe: farmland and forest. Agricultural and grassland habitats cover around 50\%, and boreal and temperate forests around 30\%, of Europe's land surface area (Tucker and Evans 1997). To reflect regional variation in habitat use by birds, we adopted a species-habitat classification based on assessments within biogeographical regions of Europe, which were then combined to create a single European classification. Expert ornithologists acted as regional coordinators and were responsible for producing the regional species lists in cooperation with many other experts. Species selection was based on birds being: (1) abundant and widespread - species with $>50,000$ breeding pairs in Europe were considered as widespread/common; (2) characteristic of farmland or forest, or other common species in Europe and per biogeographical region using an assessment of predominant regional habitat use. In each case, characteristic species are those where $\geqslant 50 \%$ of the European or regional population uses a particular habitat for breeding or feeding, according to experts. This information allowed us to create a single common habitat classification for European bird species, but also regional versions of the classification that reflected regional variation in habitat use by birds. As we illustrate below, the derived indicators based on the two approaches are in fact very similar. In time, the PECBMS plans to move to a more integrated biogeographical system for data analysis and presentation expanding upon the current regional approach to consider four biogeographical regions, Atlantic, Boreal, Continental and Mediterranean.

\section{Trends of widespread birds in Europe}

In what is the third set of European indices, the '2007 update', 124 species were classified as: 'common farmland species' (33), 'common forest species' (28), or 'other common species' (63). European species trends are available via: http://www.ebcc.info/index.php? ID $=148$. The multispecies indicators show that, on average, widespread birds as a whole are in moderate decline in Europe (Fig. 5). Average population levels have fallen by $15 \%$ over the last 25 years. Common birds living in forests have declined on average by $14 \%$, while common birds living in farmland have fallen steeply, by $43 \%$ in 25 years. Looking at the trend in farmland birds in detail, numbers fell rapidly from 1980 to about 1995, but their average population levels have been roughly stable in the last decade. At a regional level in Europe, the patterns of decline in farmland birds are similar (Fig. 6). There is a suggestion that recent trends in southern Europe are more positive, but we have to be cautious in interpretation because the trends are imprecise and the time series short. Trends among farmland birds in new and old EU countries first show divergence, but then in the last decade they converge (Fig 7a). The break up of the former Eastern Bloc around 1990 appears to have had a positive effect on farmland bird populations in that region (Gregory et al. 2005), and yet the last decade marks a further turning point and farmland birds are once again threatened by the intensification of farming methods in eastern Europe. There is a great deal of evidence to suggest that the main driver of change for these birds has been agricultural intensification and specialisation (Aebischer et al. 2000, Vickery et al. 2004). Reform of the Common Agricultural Policy in Europe provides a possible mechanism for recovery.

Trends among common forest birds also show regional variation. While on average populations have been stable in the west and east of Europe, they show considerable declines in the north and south, probably for quite different reasons (Fig. 8). Trends in old and new EU countries do not differ (Fig $7 \mathrm{~b}$ ). The explanation seems to be that there is no single policy driver 


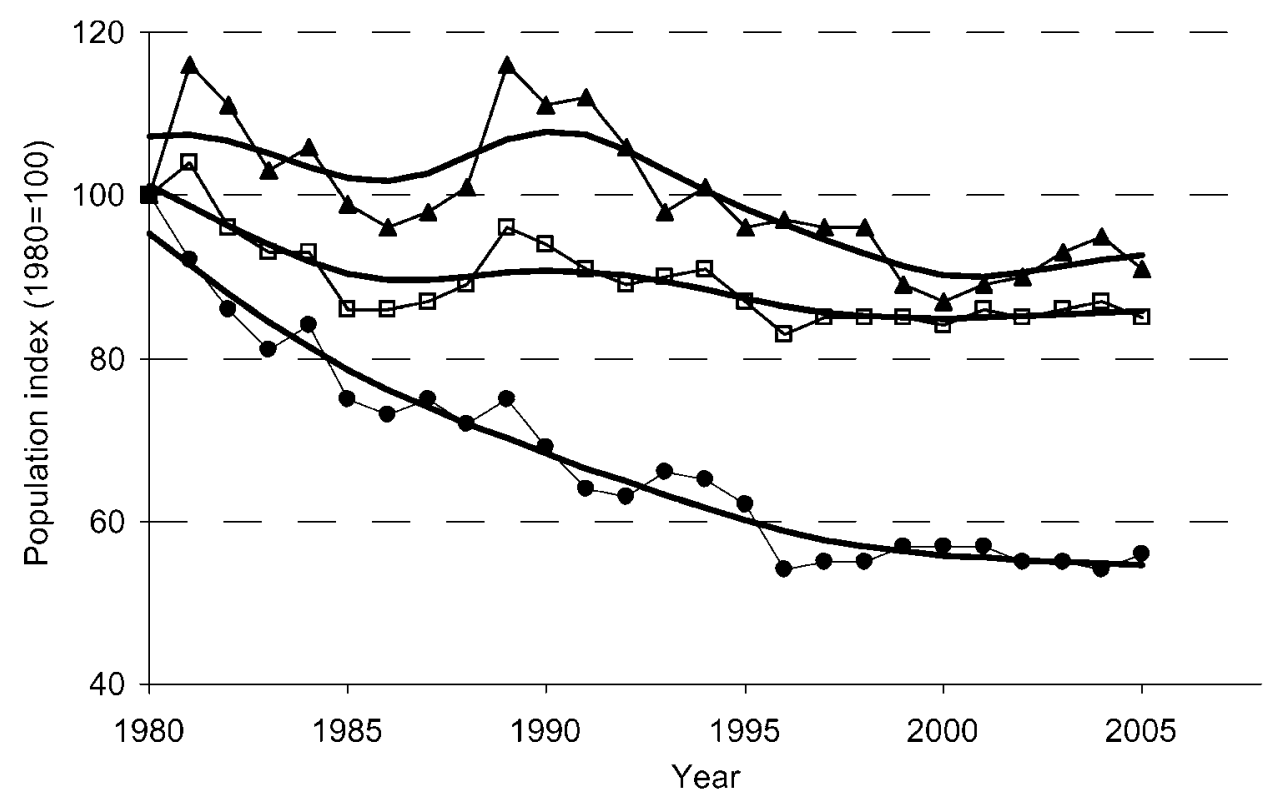

Figure 5. European wild bird indicator showing the populations trends of common forest species $(n=28$, triangular symbols, $-14 \%)$, all common species $(n=124$, square symbols, $-15 \%)$, and common farmland species $(n=33$, circular symbols, $-43 \%) . n=$ number of species included in each multi-species indicator. Bold lines represent the statistically smoothed trends. Change figures are percentage changes in the smoothed trend from 1980 to 2005. Trends were smoothed using the program TrendSpotter, which is based on structural time series analysis and the Kalman filter (Visser 2004). The computation procedure was based on four regions - West: Ireland, UK, Netherlands, Denmark, Austria, Switzerland, former West Germany, Belgium; North: Sweden, Finland, Norway; East/Central: former East Germany, Estonia, Latvia, Poland, Czech Republic, Hungary; South: France, Spain, Portugal, Italy. Data available from Estonia covered a limited number of species and the period to 2000. All countries are EU Member States, except Norway and Switzerland.

for forests in Europe (as there is for farmland) and different factors are at play. In the north, for example, many forest birds are threatened by highly intensive forestry exploitation (Angelstam et al. 2004a, 2004b). In the south, where the trend patterns are much less certain and data more sparse, wild fires, logging and built development may be relevant threats (Tucker and Evans 1997). We need more research to improve our understanding of the patterns and drivers of trends in forest birds and other taxa (Gregory et al. 2007).

\section{Turning science into policy}

As in the UK, the development of the wild bird indicators in Europe involved a crucial dialogue between the scientists and policy makers; advice from the European Environment Agency, the European Topic Centre on Biological Diversity and the European Commission, in particular, has been instrumental in guiding the PECBMS. The involvement of key policy makers from the outset has enabled us to develop summary statistics and information that specifically target the policy needs. By maintaining this focus, and demanding the highest scientific standards in data collection, analysis and peer review, the PECBMS has been successful in promoting the official 

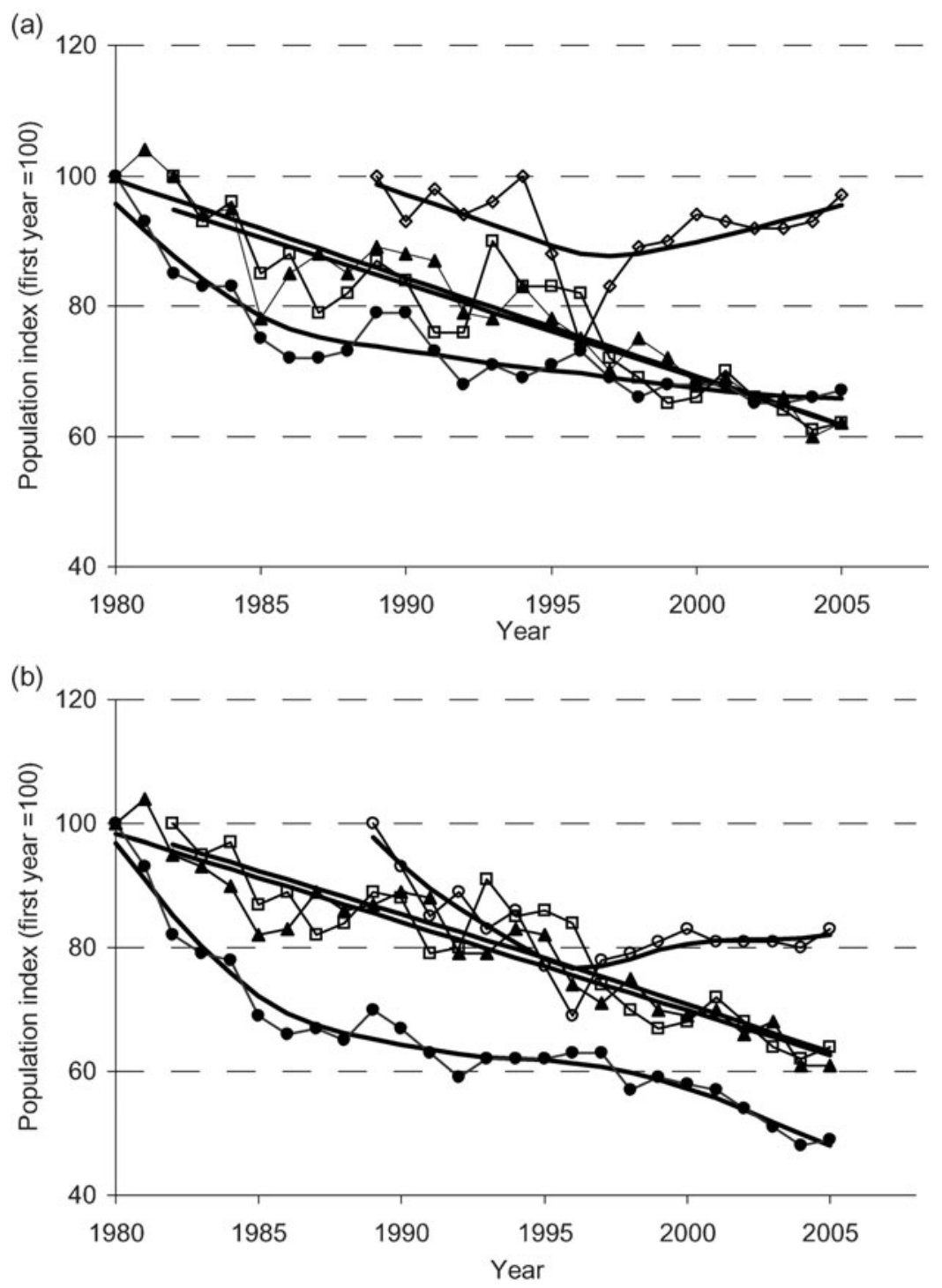

Figure 6. Regional European wild bird indicator showing the population trends of (a) common farmland species in west $(n=25$, filled circles, $-31 \%)$, east $(n=20$, open squares, $-35 \%)$, north $(n=12$, filled triangles, $-38 \%)$, and south of Europe $(n=41$, open circles, $-3 \%)$, using region-specific species lists. Then (b) common farmland species in west $(n=23$, filled circles, $-50 \%)$, east $(n=23$, open squares, $-35 \%)$, north $(n=13$, filled triangles, $-36 \%)$, and south of Europe $(n=33$, open circles, $-16 \%)$, using a single European species list. $n=$ number of species included in each multi-species indicator. Bold lines represent the statistically smoothed trends. Change figures are percentage changes in the smoothed trend from 1980 to 2005 (west and north), 1982-2005 (east) and 1989-2005 (south).

use of its biodiversity indicators in Europe. To do this, the indices have had to meet a range of quality criteria, both statistical and in terms of country representation. The farmland bird index has been adopted by the EU as a baseline indicator under the Rural Development Regulations 


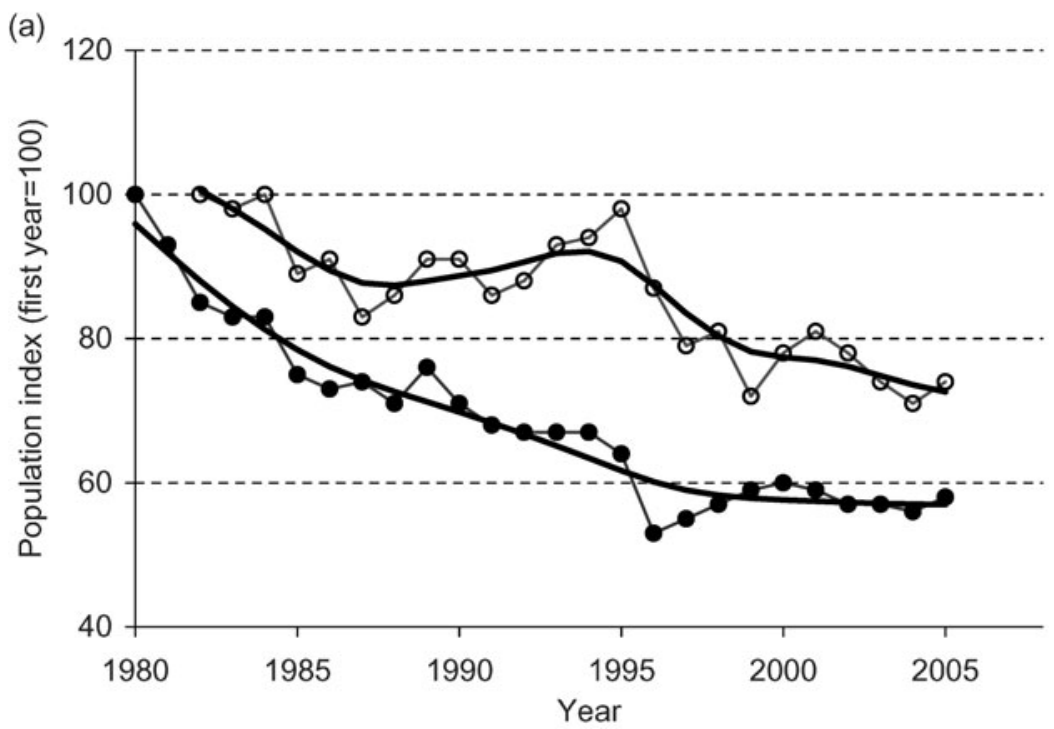

(b)

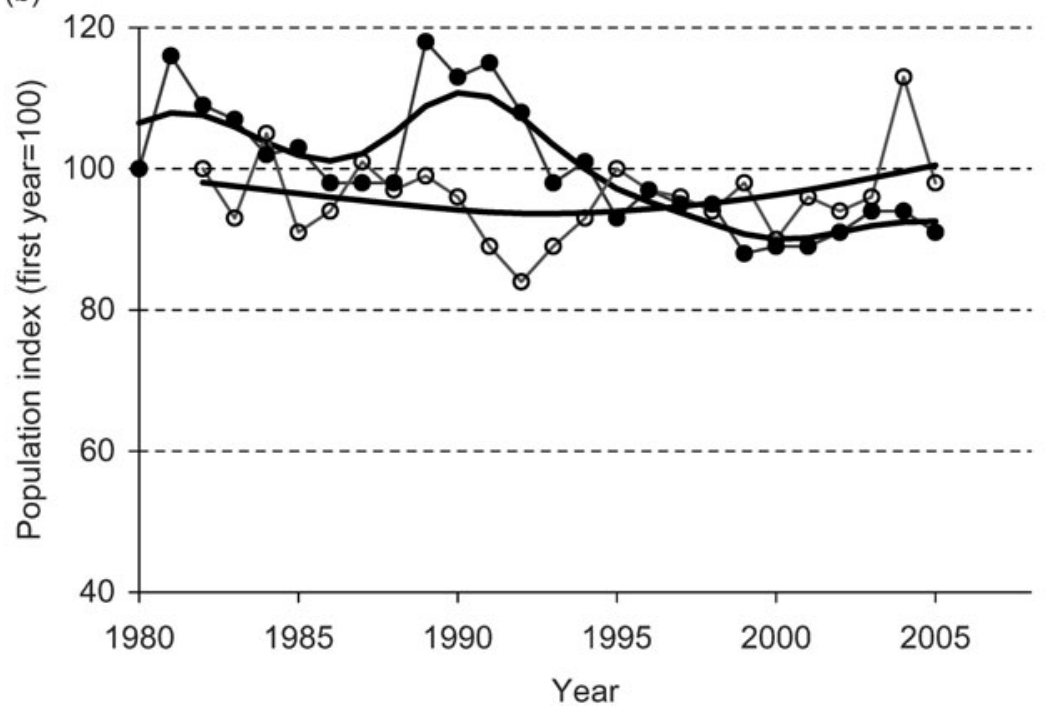

Figure 7. Populations trends of wild birds in the 'old' and 'new' EU countries for a) common farmland birds in old EU $(n=33$, filled circles, $-41 \%)$, new EU $(n=23$, open circles, $-28 \%)$, and b) common forest birds in new EU $(n=28$, filled circles, $-13 \%)$, new EU $(n=25$, open circles, $+3 \%)$. $n=$ number of species included in each multi-species indicator. Bold lines represent the statistically smoothed trends. Change figures are percentage changes in the smoothed trend from 1980 to 2005 (old EU) and 1982-2005 (new EU). The new Member States joining in 2004 are Estonia, Latvia, Poland, Czech Republic and Hungary.

and as a Sustainable Development and Structural Indicator (http://epp.eurostat.ec.europa.eu/ portal/page?_pageid=1090,30070682,1090_33076576and_dad=portaland_schema $=$ PORTAL). Rural Development Regulations, for example, require EU member states to develop a plan for agriculture that is measured against operational farmland bird indices. The wild bird indices 

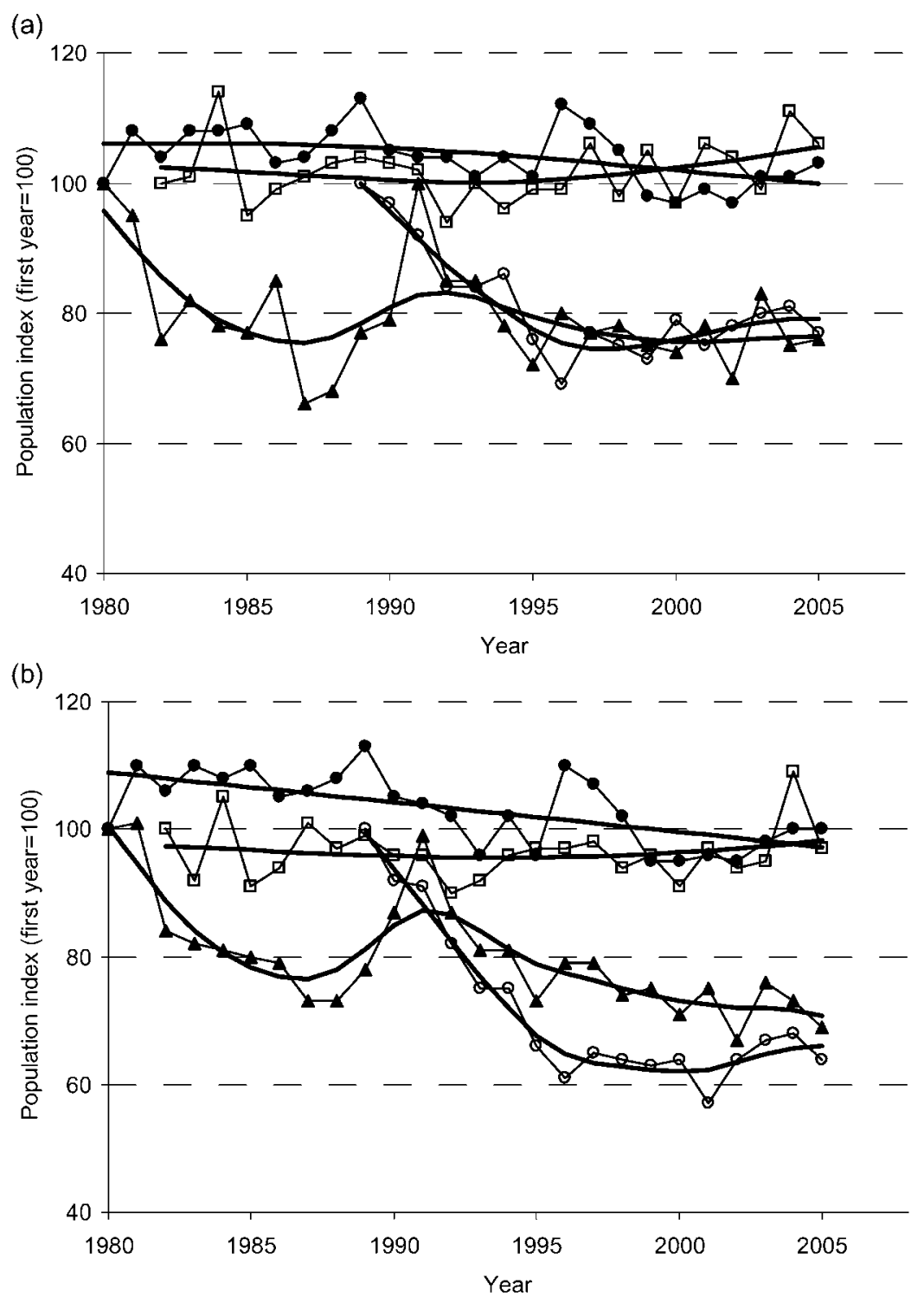

Figure 8. Regional European wild bird indicator showing the population trends of (a) common forest species in west $(n=30$, filled circles, $-6 \%)$, east $(n=34$, open squares, $+3 \%)$, north $(n=$ 15 , filled triangles, $-20 \%)$, and south of Europe $(n=29$, open circles, $-21 \%)$, using regionspecific species lists. Then (b) common forest species in west $(n=26$, filled circles, $-11 \%)$, east ( $n=25$, open squares, $+1 \%)$, north $(n=22$, filled triangles, $-30 \%)$, and south of Europe $(n=$ 21 , open circles, $-34 \%$ ), using a single European species list. $n=$ number of species included in each multi-species indicator. Bold lines represent the statistically smoothed trends. Change figures are percentage changes in the smoothed trend from 1980 to 2005 (west and north), 19822005 (east) and 1989-2005 (south). 
also feature in the so-called SEBI2010 (Streamlining European 2010 Biodiversity Indicators) set of biodiversity indicators. A pan-European initiative led by the European Environment Agency, SEBI2010 aimed to develop an intelligent set of indicators to assess progress towards the European target of halting biodiversity loss by 2010 . The first phase of work proposed 26 biodiversity indices within the framework of the CBD (http://biodiversity-chm.eea.europa.eu/ information/indicator/F1090245995). This process provides a good example of how operational indicators can be sensibly developed. What we need next, however, is a stronger commitment from the EU to support indicator production, and from EU and national governments to help turn ambitions for biodiversity conservation into more tightly defined targets and integrated recovery plans.

Our work has also helped to catalyse development and adoption of wild bird indicators in other European countries too. In Sweden, for example, the government has adopted 16 environmental objectives, four of which are underpinned by common bird indices at national and regional levels (covering forests, agriculture, uplands, and general biodiversity: http:// miljomal.nu/Pub/IndikatorList.php). France is using an indicator system where species are grouped by habitat and specialism (http://www.mnhn.fr/vigie-nature/STOC_indicateurs.htm). In The Netherlands, a number of indicators for many kinds of habitats and species groups have been formulated, and although the government reports on them annually, they do not have formal status, nor do they have targets (see www.natuurcompendium.nl for examples). Similar frameworks are being used and developed in a number of other European countries.

The wild bird indicators presented here are the first headline indicators of their kind in Europe and they remain the only ones adopted at such high levels. Having biodiversity considered by politicians in this way is a significant advance, and we hope it will bring positive benefits to biodiversity conservation and sustainable land use, as we are starting to see in some countries. The strengths of this approach are its simplicity, transparency, temporal sensitivity, scientific credibility, policy relevance, relative ease of update, and, critically, the clarity of message. Wild bird indicators have shown their ability to connect and communicate with the public and decision makers alike, allowing policy makers to understand changes in the environment and then make better decisions about how we manage natural resources.

\section{Discussion}

\section{The success of wild bird indicators so far}

The state indicators based on wild bird populations, shown above for the UK and Europe and developed in other European countries, have been very successful in reporting on trends in one element of biodiversity and thus influencing policy at a range of levels, as well as communicating to a wider, non-specialist audience. Naturally, our indices need to be supported by complementary information on other aspects of species, sites and habitat conservation. Frequent updates (i.e. annual in the UK) have made the wild bird indicator familiar to both policy-makers and the general public, and new updates are often reported by national media. The indicators have been particularly valuable in highlighting the decline in farmland bird populations, driven in the main by agricultural intensification. In addition, a common pattern emerging from the work in UK and Europe is of some generalist birds doing well, but many specialists doing badly. The increasing prevalence of a small number of widespread opportunistic species - a process termed 'biotic homogenisation' (McKinney and Lockwood 1999, Van Turnhout et al. 2007) - is of particular concern given that we know little about the long-term consequences of these changes on other components of biodiversity and on ecosystem services.

The regional/sub-national versions of wild bird indicators, within Europe or within the UK, paint a mixed picture of how the environment is changing. Problems of species selection and application at different spatial scales and in different systems complicates comparisons, and 
highlights the need for involving experts in their production and interpretation. Nevertheless, although population trends for individual species (and by extension particular landscapeassociated indicators) will be influenced by a diverse array of factors, these approaches have proved successful in identifying the main drivers of change in the group of species included in the indicators. To identify and understand the effects of particular issues in, for example, management of old-growth forests or the impact of commercial fishing on birds, it will always be necessary to disaggregate the headline indicator into sub-groups of species and to individual species that are expected to show the strongest response to a particular driver, and to carry out more detailed research.

\section{Potential for future development of wild bird indicators in the UK and Europe}

There is a vast range of potential indicators, with new developments at different spatial scales in different habitats and in different seasons. Although most current wild bird indicators focus on breeding population changes, those based on wintering populations, (which are important features of biodiversity in many countries and often show markedly different trends from those in breeding populations), may show how changes in climate and habitat are affecting the distribution and numbers of wintering birds. Changes in conditions over the winter may have a significant impact on breeding populations, by reducing survival or subsequent productivity, and demonstrate the need to monitor these demographic parameters where possible to help identify the main threats. Such developments are already underway for seabirds, where changes in productivity may be considerably more sensitive and responsive to environmental change than changes in breeding numbers of these relatively long-lived species. Other possibilities include developments in indices of biotic homogenisation that capture the additive effects of increases in generalist species and declines in specialists.

Another possibility is a return to ideas based on an approach of combining data series reflecting 'distance to target' for key species and habitats (Bibby 1999), first considered in the development of the UK wild bird indicators. One of the advantages of the distance to target approach is that in principle it allows data on different taxa to be combined with data on the condition of different habitats. Another clear advantage is that it is possible to set targets for both increase, or decrease. The latter may be applicable when we judge populations are too large, as might be the case for generalist, or pest species, which are insensitive or even benefit from anthropogenic modifications in the landscape (McKinney and Lockwood 1999). The disadvantages include the need to define targets, which are problematical both on theoretical and practical grounds, and the need for high quality trend data for a range of species and habitats. In the UK, at least, it is difficult to see how we would find consensus on targets among the relevant government agencies and NGOs in a timely fashion. Underhill and Crawford (2005), however, successfully used a target-based approach to index environmental health for breeding seabirds in the Benguela ecosystem. Similarly, van Strien (1999) and Ten Brink (2000) described an Ecological Capital Index that combined information on the quality and quantity of a habitat in a single statistic. Quality was taken to be the density of habitat-specific species and quantity was the area of that habitat. Rare and common species were included and their current densities were contrasted with a reference situation in the past, which is equivalent to the distance to target indices above. Two of the practical issues with this index were the choice of the reference period, which must to some degree to be a subjective judgement, and the selection of the habitat-specific species. Despite this, the index captures much of what we think about in terms of environmental change.

If we consider threats to biodiversity more broadly, invasive alien species are a major factor in many situations and localities. In Europe, at least, our knowledge of introduced bird species might allow us to develop indicators based on their population trends. This would allow us to track their numbers through time and might alert us to emerging problems and gauge 
potential impacts. In general, we lack good information on the abundance of invasive species.

A further development of this approach would be the creation of climate change impact indicators based on models that identify climate sensitivity in species and make predictions about population trends.

\section{Challenges facing the use and development of biodiversity indicators in Europe and beyond}

Headline indicators of any kind will only work when they are few in number. Considering biodiversity, very few indicators are currently available at the European level that could act as genuine headline indicators. The farmland bird indicator is the exception and it is already well established. Several other biodiversity indicators are in development, including a Red List indicator (Butchart et al. 2004, 2007), and work is underway to produce European butterfly indicators for several habitat types (van Swaay and van Strien 2005, van Swaay et al. 2006). In the longer run, other species groups may possibly be added, such as bats, large mammals, fish, and whales.

There are already calls from decision makers in Europe for a single biodiversity indicator with a clear message for the general public, which somehow combines information on different species groups and their habitats. We will need to think very carefully about sensible combinations of species groups, taking into account differences in such issues as precision and accuracy of the underlying data, species response times, numbers of species per group, phylogenetic uniqueness, and the need for weighting. Sensible combinations could be made by habitat type, with, for example, specialists of farmland recruited from different taxa, but one might also wish to combine species that respond strongly to similar environmental drivers, such as species sensitive to climate change, or to habitat fragmentation. On top of this, one might also wish to incorporate changes in habitat extent and quality in some fashion: clearly, a good deal of careful consideration will be required.

A further challenge arises if the bird indicators were to be expanded to cover wider geographical regions and in time to produce continental or global wild bird indicators, an ambition currently being promoted and developed by BirdLife International and the RSPB. Indeed, Pereira and Cooper (2006) recommended the use of birds with vascular plants, as part of a new global biodiversity monitoring network responding to the 2010 targets. Information on continent-wide trends of common bird species is available for Europe, as well as for North America, and perhaps beyond in some form. BirdLife's global wild bird indicator project aims to develop indices from existing national or sub-national monitoring data, to set up tools to implement similar data collection and synthesis across a representative set of countries in other regions (building upon the an existing system using: http://worldbirds.org/ WorldMap.php? $\mathrm{m}=\mathrm{o}$ ), and to develop prototype indicators from these data sources. In many parts of the world, however, one might expect data for widespread birds to be collected from only a limited number of sites, where most probably the species composition will vary considerably between the sites. It is then much more difficult to use this information to assess supranational trends as we have done in Europe. We would then need to think carefully about combining the site/habitat-specific trends, with habitat-specific trends for species groups at different scales. There is more work to do on the design and implementation of regional and global wild bird monitoring, but our ambitions are clear.

Composite trend indicators, such as the wild bird indicators, provide a simple way of measuring progress towards targets of reducing biodiversity loss at a number of spatial scales. These are the first biodiversity indicators of their kind in Europe and probably around the globe. They consider one element of bird diversity and one tiny element of biodiversity, and yet they demonstrate how workable indicators can inform decision makers, and improve the management of natural resources. At a deeper level, however, the degree to which birds can represent other elements and trends in biodiversity is less clear. We really do not know how well the indicators 
we describe would work in other habitats and in other parts of the world. Certainly, birds have many useful characteristics that make them good potential indicators, including their public appeal, ease of identification and survey, their relative abundance, moderate diversity, and our level of knowledge about their ecology, numbers and ranges. At the same time, birds use the environment in a fashion and at a spatial scale quite unlike most other taxa. They are highly mobile and many species are migratory thus integrating environmental changes over huge areas. It is unclear how the spatial and temporal changes in bird numbers correspond with those of other taxa, and surprisingly there is little direct evidence on this critical question. Given these uncertainties, we must promote and use wild bird indicators in a careful and cautious fashion (Gregory et al. 2005, 2007). That said, the work we describe is a great example of successful collaboration in applied conservation science, which is communicating information on biodiversity trends in Europe, and is part of a concerted effort to improve the state of nature worldwide.

\section{Acknowledgements}

The wild bird indicators developed in the UK and its constituent countries are the result of longterm collaboration between a group of organisations. The key organisations involved are the Royal Society for the Protection of Birds (RSPB), the British Trust for Ornithology (BTO) and the Department of Environment and Rural Affairs (Defra), with valuable contributions from the Joint Nature Conservation Committee (JNCC), and the Wildfowl and Wetlands Trust (WWT). The data used in the UK indicators are collected almost entirely by volunteer birdwatchers carrying out surveys coordinated by these organisations as well as from information collected by the Rare Breeding Birds Panel and a suite of special surveys.

The Pan-European Common Bird Monitoring Scheme (PECBMS) is a partnership involving the European Bird Census Council, the RSPB, BirdLife International, and Statistics Netherlands. The European Commission and the RSPB fund the PECBMS. The success of this project owes much to the co-operation, goodwill and expertise of the network, and we thank all those responsible for national data collation and analysis, and to the many thousands of skilled volunteer counters responsible for data collection. Special thanks to the data providers and organisations responsible for national data collection and analysis: Norbert Teufelbauer, Michael Dvorak, Christian Vansteenwegen, Anne Weiserbs, Jean-Paul Jacob, Anny Anselin, Thierry Kinet, Anotoine Derouaux, Jiri Reif, Karel Stastny, Henning Heldbjerg, Michael Grell, Andres Kuresoo, Risto Väisänen, Frederic Jiguet, Johannes Schwarz, Martin Flade, Tibor Szep, Olivia Crowe, Lorenzo Fornasari, Elisabetta de Carli, Ainars Aunins, Magne Husby, Przemek Chylarecki, Dagmara Jawinska, Geoff Hilton, Juan Carlos del Moral, Ramón Martí, Virginia Escandell, Åke Lindström, Sören Svensson, Hans Schmid, and Mike Raven. We also thank David W. Gibbons, Dominique Richard, Grégoire Lois, Pierre Nadin, Laure Ledoux, and Anne Teller for valuable comments and support. We thank an anonymous referee for constructive comments.

\section{References}

Aebischer, N. J., Evans, A. D., Grice, P. V. and Vickery, J. A. (Eds.) (2000) Ecology and conservation of lowland farmland birds. Tring, UK: British Ornithologists Union.

Angelstam, P., Boutin, S., Schmiegelow, F., Villard, M.-A., Drapeau, P., Host, G.,
Innes, J., Isachenko, G., Kuuluvainen, Mönkkönen, Niemela, J., Niemi, G., Roberge, J.-M., Spence, J. and Stone, D. (2004a) Targets for boreal forest biodiversity conservation - a rationale for macroecological research and adaptive management. Ecol. Bull. 51: 487-509. 
Angelstam, P., Dönz-Breuss, M. and Roberge, J.-M. (2004b) Targets and tools for the maintenance of forest biodiversity - an introduction. Ecol. Bull. 51: 11-24.

Balmford, A., Bennun, L., ten Brink, B., Cooper, D., Côté, I. M., Crane, P., Dobson, A., Dudley, N., Dutton, I., Green, R. E., Gregory, R. D., Harrison, J., Kennedy, E. T., Kremen, C., Leader-Williams, N., Lovejoy, T. E., Mace, G., May, R., Mayaux, P., Morling, P., Phillips, J., Redford, K., Ricketts, T. H., Rodríguez, J. P., Sanjayan, M., Schei, P. J., van Jaarsveld, A. S. and Walther, B. A. (2005) The Convention on Biological Diversity's 2010 Target. Science 307: 212-213.

Bibby, C. J. (1999) Making the most of birds as environmental indicators. Ostrich 70 : $81-88$.

BirdLife International (2004) Birds in Europe: population estimates, trends and conservation status. Cambridge, UK: BirdLife International. (BirdLife Conservation Series No. 12).

Butchart, S. H. M., Akcakaya, H. R., Chanson, J., Baillie, J. E. M., Collen, B., Quader, S., Turner, W. R., Amin, R., Stuart, S. N. and Hilton-Taylor, C. (2007) Improvements to the Red List Index. PLoS ONE 2(1): eI4O doi:10.1371/journal. pone.0000140.

Butchart, S. H. M., Stattersfield, A. J., Bennun, L. A., Shutes, S. M., Akcakaya, H. R., Baillie, J. E. M., Stuart, S. N., Hilton-Taylor, C. and Mace, G. M. (2004) Measuring global trends in the status of biodiversity: Red List Indices for birds. PLoS Biology 2: e383.

Caro, T. M. and O'Doherty, G. (1998) On the use of surrogate species in conservation biology. Conserv. Biol. 13: 805-814.

Carpenter, S. R., DeFries, R., Dietz, T., Mooney, H. A., Polasky, S., Reid, W. V. and Scholes, R. J. (2006) Millennium Ecosystem Assessment: Research needs. Science 314: 257-258.

Furness, R. W. and Greenwood, J. J. D. (Eds.) (1993) Birds as monitors of environmental change. London: Chapman and Hall.

Gibbons, D. W. (1998) Pan-European breeding bird monitoring. Bird Census News 11: $42-45$.
Gibbons, D. W. (2000) Development of panEuropean breeding bird monitoring. The Ring 22: 25-33.

Gregory, R. D. and Vořišek, P. (2003) Report on the Pan-European common bird monitoring workshop. Bird Census News 16: 2-13.

Gibbons, D. W., Reid, J. B. and Chapman, R. A. (1993) The new atlas of breeding birds in Britain and Ireland: 1988-1991. London: Tand AD Poyser.

Gregory, R. D., Gibbons, D. W., Impey, A. and Marchant, J. H. (1999) Generation of the headline indicator of wild bird populations. BTO Research Report 221. Thetford and Sandy, UK: BTO and RSPB.

Gregory, R. D., Noble, D. A. and Custance, J. (2004) The state of play of farmland birds: population trends and conservation status of farmland birds in the United Kingdom. Ibis 146 (Suppl. 2): 1-13.

Gregory, R. D., Noble, D., Field, R., Marchant, J. H., Raven, M. and Gibbons, D. W. (2003) Using birds as indicators of biodiversity. Ornis Hungaria 12-13: 11-24.

Gregory, R. D., van Strien, A. J., Vořrišek, P., Gmelig Meyling, A. W., Noble, D. G., Foppen, R. P. B. and Gibbons, D. W. (2005) Developing indicators for European birds. Phil. Trans. R. Soc. Lond. B. 360: 269-288.

Gregory, R. D., Vořišek, P., van Strien, A. J., Gmelig Meyling, A. W., Jiguet, F., Fornasari, L., Reif, J., Chylarecki, P. and Burfield, I. J. (2007) Population trends of widespread woodland birds in Europe. Ibis 149 (Suppl. 2): 78-97, doi: 10.1111/j.1474-919x. 2007.00698.x.

Hilty, J. and Merenlender, A. (2000) Faunal indicator taxa selection for monitoring ecosystem health. Biol. Conserv. 92: 185-197.

Hustings, F. (1988) European monitoring studies on breeding birds. SOVON, BeekUbbergen, the Netherlands.

Hustings, F. (1992) European monitoring studies on breeding birds: an update. Bird Census News 2: 1-56.

Landres, P. H., Verner, J. and Thomas, J. W. (1988) Ecological uses of vertebrate indicator species-a critique. Conserv. Biol. 2: 316-328.

Lindenmayer, D. B., Margules, C. R. and Botkin, D. B. (2000) Indicators of 
biodiversity for ecologically sustainable forest management. Conserv. Biol. 14: 941-950.

McClenahen, J. R., Davis, D. D. and Hutnik, R. J. (2007) Macrolichens as biomonitors of air-quality change in western Pennsylvania. Northeastern Naturalist 14: 15-26.

McKinney, M. L. and Lockwood, J. L. (1999) Biotic homogenization: a few winners replacing many losers in the next mass extinction. Trends Ecol. Evol. 11: 450-453.

Newson, S. E., Noble, D. G. and Eaton, M. A. (2004) Preliminary BBS-based habitatspecific indicators for wild bird populations: 1994-2002. Thetford, UK: BTO. BTO Research Report No. 368.

Nichols, J. D. and Williams, B. K. (2006) Monitoring for conservation. Trends Ecol. Evol. 21: 668-673.

Pannekoek, J. and van Strien, A. J. (2001) TRIM 3 Manual. Trends and Indices for Monitoring Data. Research paper no. 0102. CBS Voorburg, The Netherlands: Statistics Netherlands. (Available at www.ebcc.info).

Pereira, H. M. and Cooper, H. D. (2006) Towards the global monitoring of biodiversity change. Trends Ecol. Evol. 21: 123-129.

ten Brink, B. J. E. (2000) Biodiversity indicators for the OECD: Environmental outlook and strategy, a feasibility study. Bilthoven, The Netherlands: National Institute for Public Health and the Environment. RIVM report 402001014.

Tucker, G. M. and Evans, M. I. (1997) Habitats for birds in Europe: a conservation strategy for the wider environment. Cambridge, UK: BirdLife International (BirdLife Conservation Series No. 6).

Tucker, G. M. and Heath, M. F. (1994) Birds in Europe: their conservation status.
Cambridge, UK: BirdLife International (BirdLife Conservation Series No. 3).

Underhill, L. G. and Crawford, R. J. M. (2005) Indexing the health of the environment for breeding seabirds in the Benguela ecosystem. ICES J. Marine Sci. 62: 360-365.

van Strien, A. J. (1999) From monitoring data to policy-relevant summary statistics. Bird Numbers 1998. Vogelwelt 120: 67-71.

van Strien, A. J., Pannekoek, J. and Gibbons, D. W. (2001) Indexing European bird population trends using results of national monitoring schemes: a trial of a new method. Bird Study 48: 200-213.

van Swaay, C. and van Strien, A. (2005) Using butterfly monitoring data to develop a European grassland butterfly indicator. Pp. 106-108 in E. Kuehn, J. Thomas, R. Feldmann and J. Settele, eds. Studies on the Ecology and Conservation of Butterflies in Europe. Proceedings of the Conference held in UFZ Leipzig, 5-9th of December 2005.

van Swaay, C., Warren, M. and Lors, G. (2006) Biotope use and trends of European butterflies. J. Insect Conserv. 10: 189-209. van Turnhout, C. A. M., Foppen, R. P. B., Leuven, R. S. E. W., Siepel, H. and Esselink, H. (2007) Scale-dependent homogenization: Changes in breeding bird diversity in the Netherlands over a 25 year period. Biol. Conserv. 134: 505-516.

Vickery, J. A., Evans, A. D., Grice, P., BrandHardy, R. and Aebischer, N. A., eds. (2004) Ecology and conservation of lowland farmland birds II: The road to recovery. Ibis 146(suppl): iii-258.

Visser, H. (2004) Estimation and detection of flexible trends. Atmospheric Environ. 38: 4135-4145.

Vořišek, P. and Marchant, J. H. (2003) Review on large-scale generic population monitoring schemes in Europe. Bird Census News 16: 14-30.

\section{RICHARD D. GREGORY*}

European Bird Census Council and The Royal Society for the Protection of Birds, The Lodge, Sandy, Bedfordshire SG19 2DL, U.K.

PETR VOŘIŠEK, ALENA KLVAŇOVÁ

Czech Society for Ornithology, Na Bělidle 252/34, CZ-15o oo Prague 5, Czech Republic. 
DAVID G. NOBLE, ANDREW JOYS

British Trust for Ornithology, The Nunnery, Thetford, Norfolk, IP24 2 PU, U.K.

ARCO VAN STRIEN, ADRIAAN W. GMELIG MEYLING

Statistics Netherlands, PO Box 400o, 2270 JM Voorburg, the Netherlands.

\section{MARK EATON}

The Royal Society for the Protection of Birds, The Lodge, Sandy, Bedfordshire SG19 2DL, U.K.

RUUD P. B. FOPPEN

SOVON, Dutch Centre for Field Ornithology, Rijksstraatweg 178, 6573 DG, Beek-Ubbergen, the Netherlands.

IAN J. BURFIELD

BirdLife International, Wellbrook Court, Girton Road, Cambridge CB3 oNA, U.K.

* Author for correspondence; e-mail: richard.gregory@rspb.org.uk 